\title{
Local excision of pulmonary arteriovenous fistulae including the feeding artery and draining vein
}

\author{
A L PRIOR, J J EFTHIMIOU, AND A K YATES \\ From the Department of Thoracic Surgery, Guy's Hospital, London, UK
}

ABSTRACT Two cases of pulmonary arteriovenous fistula were treated by local anatomical dissection and excision. This technique is preferable to pulmonary resection when the fistula is localised and superficially situated. The feeding vessels must be included in the resection to avoid possible recurrence. The history of the surgical removal of arteriovenous fistulae is discussed, and the reasons for preferring local excision are given.

\section{Case reports}

CASE 1

A 31-year-old woman developed a cough in July 1971 , and a chest radiograph showed a shadow in the left lower lobe (fig 1). She was a fit woman with early clubbing of the fingers. On auscultation a continuous murmur with a loud rough systolic component was heard over her back medial to her left scapula.

Her electrocardiogram was normal. While she breathed air, her arterial oxygen tension was $75 \mathrm{mmHg}(10 \mathrm{kPa})$ and her mixed venous oxygen tension was $36 \mathrm{mmHg}(4.8 \mathrm{kPa})$. Her haemoglobin level was $15.6 \mathrm{~g} / \mathrm{dl}$ and her packed cell volume $46.9 \%$. The pulmonary arteriogram showed

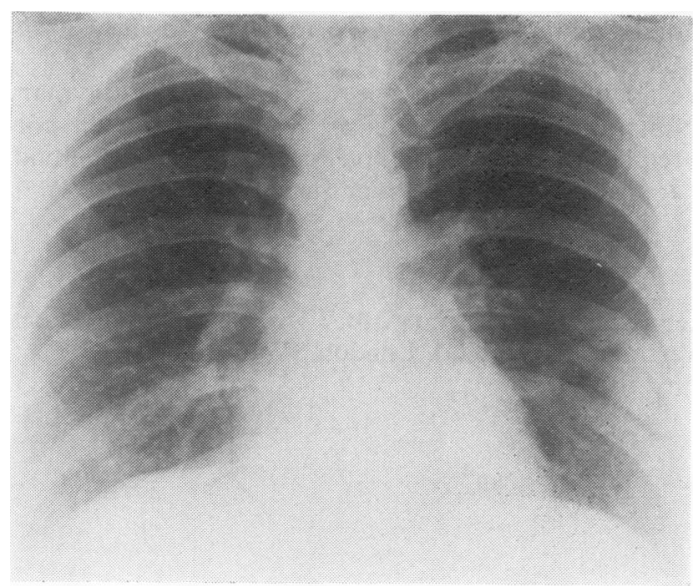

Fig 1 Case 1. Preoperative chest radiograph. a large arteriovenous fistula in the left lower $\underset{\omega}{\overrightarrow{0}}$
lobe (fig 2).

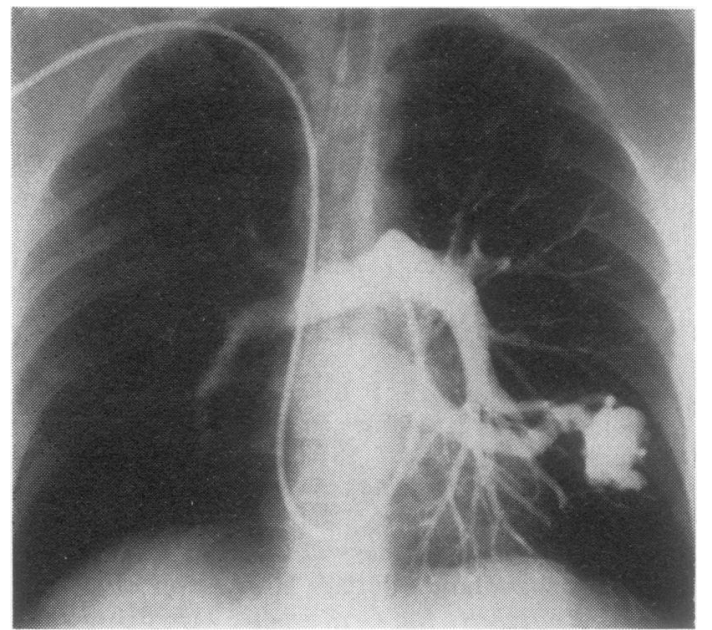

Fig 2 Case 1. Pulmonary arteriogram showing fistula in left lower lobe.

On 14 July 1971 a left posterolateral thoracotomy was performed through the fifth rib bed. $\widetilde{\gamma}$ A large arteriovenous fistula was found bulging from the pleural surface of the left lower lobe. The pulmonary artery and the veins supplying the left lower lobe were controlled and, with careful dissection, the feeding artery and large draining vein were located. These vessels were ligated and divided, and the arteriovenous fistula was excised with them. The pleural surface was closed with a running chromic catgut suture. 
Histological examination of the specimen showed vascular tissue with thick and thin walled blood vessels and a thin shell of normal but compressed lung tissue. There were several blue cysts that were of venous origin while some of the small vessels were arteries.

The patient recovered uneventfully and has been well for the past seven years.

\section{CASE 2}

On a routine examination a healthy 12 -year-old girl was found to have a cardiac murmur, early clubbing of her fingers, and central cyanosis. palpation of the heart showed increased right ventricular activity and on auscultation a continuous murmur that increased on inspiration was heard over the left precordium and left side of her back. She was smaller than her twin sister with whom she had been identical at birth.

The chest radiograph showed a shadow in the lingula that appeared to be vascular in origin (fig 3). Her haemoglobin level was $16.7 \mathrm{~g} / \mathrm{dl}$ and the packed cell volume $27 \cdot 8 \%$. While breathing air the arterial oxygen tension was $45 \mathrm{mmHg}(6 \mathrm{kPa})$. The pulmonary arteriogram confirmed the presence of an arteriovenous fistula in the left lower lobe (fig 4).

A left posterolateral thoracotomy was performed through the fifth rib bed. A large arteriovenous fistula was found on the fissural surface of the lingular segment of the upper lobe. The pulmonary artery was dissected and controlled with a tape. The oblique fissure was developed in such a way as to expose the left upper lobe branches of the pulmonary artery. The artery supplying the fistula was recognised in the hilum by collapse of

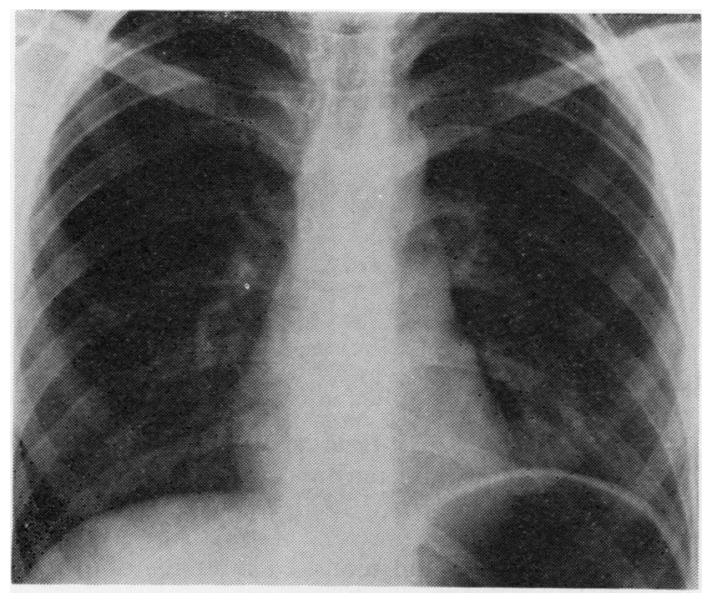

Fig 3 Case 2. Preoperative chest radiograph.

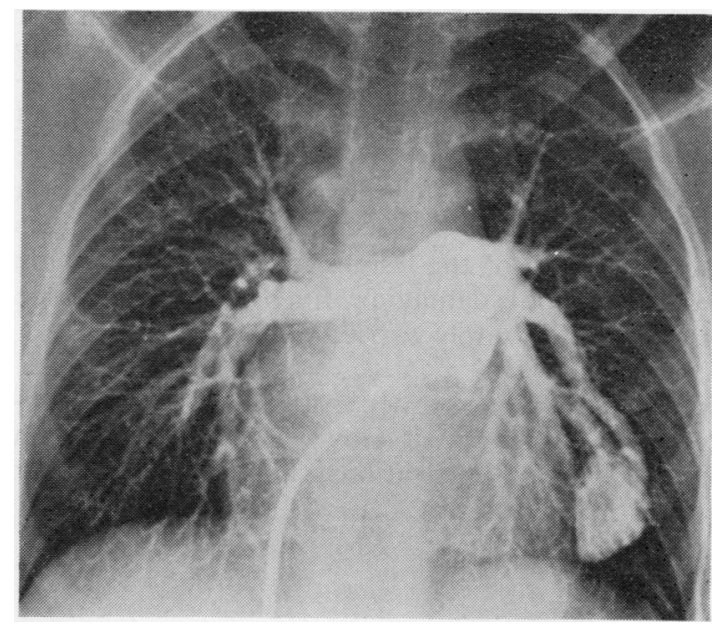

Fig 4 Case 2. Pulmonary arteriogram showing arteriovenous fistula in lingula.

the fistulous sac when the vessel was occluded. The draining vein was dissected. Both artery and vein were ligated and the fistulous sac excised with the vessels. The pleural edges were approximated using interrupted mersilene sutures.

The patient made an excellent recovery and is well eight months after the operation.

\section{Discussion}

The first operation for a pulmonary arteriovenous fistula was a pneumonectomy performed by Shenstone in 1940 (Hepburn and Dauphinee, 1942). More localised resections are preferable, the ideal being the removal of the lesion and the preservation of the surrounding functional lung tissue. In 1941 and 1942 Janes (1944) removed arteriovenous fistulae by local resections from the left and right lungs of the same patient, leaving the feeding vessels. This is not ideal because a recurrence may occur from small fistulae between these vessels, but this patient did well. In July 1948 Blalock (Sloan and Cooley, 1953) performed the first segmental resection for a pulmonary arteriovenous fistula.

Crafoord (1950) called attention to the technique of isolating the blood supply to the lobe or lung to render the region bloodless and to allow safe and rapid dissection of the lesion with its feeding vessels. Parker and Stallworth in 1952 reported the first case in which the fistulous sac along with the afferent artery and efferent vein was excised without sacrificing any pulmonary tissue.

Despite the fact that local resection of these lesions intact with their feeding vessels can be 
performed successfully and safely, lobectomy or segmental resection are the operations usually recommended (Sabiston and Wolfe, 1976). Bosher et al (1959) in their survey of 350 cases showed that 89 out of 110 cases (where suitable data were available) were superficial enough to allow excision without pulmonary resection. In our two cases local resection of the lesions including the feeding vessels without damaging functional lung tissue was easily and safely carried out.

We thank the $x$-ray department and the photographic department of Guy's hospital for help in producing our illustrations, and Mrs Prior for typing the manuscript.

\section{References}

Bosher, L H, Blake, D A, and Byrd, B R (1959). An analysis of the pathologic anatomy of pulmonary arteriovenous aneurysms with a particular reference to the applicability of local excision. Surgery, 45, 91-104.

Crafoord, C (1950). In discussion of paper by Lindskog et al.
Hepburn, J, and Dauphinee, J A (1942). Successfuff removal of hemangioma of the lung followed bie disappearance of polycythemia. American Journa of the Medical Sciences, 204, 681-685.

Janes, R M (1944). Multiple cavernous haemangioma of the lungs successfully treated by local resection of the tumours. British Journal of Surgery, 31 $1_{2}^{\text {s }}$ $270-275$.

Lindskog, G E, Liebow, A, Kausel, H, and JanzenA (1950). Pulmonary arteriovenous aneurysm Annals of Surgery, 132, 591-610.

Parker, E F, and Stallworth, J M (1952). Arterio venous fistula of the lung treated by dissection and excision without pulmonary excision. Surgery, 32 i 31-38.

Sabiston, D C, and Wolfe, W G (1976). Pulmonary embolism. In Gibbon's Surgery of the Chest, 3rdo edn, edited by D C Sabiston and F C Spencer, p 631. Saunders, Philadelphia.

Sloan, R D, and Cooley, R N (1953). CongenitaR pulmonary arteriovenous aneurysm. American Journal of Roentgenology, 70, 183.

Requests for reprints to: A L Prior, FRCS, Depart-ç ment of Thoracic Surgery, Guy's Hospital, St Thomas Street, London SE1.

\section{Correction}

Liang, A et al. Transit-time analysis of the forced expiratory spirogram during clinical remission in $\mathbb{\mathbb { D }}$ juvenile asthma. Thorax, 1979, 34, 194-199.

Line 13 page 195 should read . . intervals of $100 \mathrm{~ms}$ and each corresponding volume...

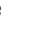

